\title{
Gold nanoparticles prepared by laser ablation in aqueous biocompatible solutions: assessment of safety and biological identity for nanomedicine applications
}

\author{
This article was published in the following Dove Press journal: \\ International Journal of Nanomedicine \\ 21 November 2014 \\ Number of times this article has been viewed
}

Florian Correard ${ }^{1,2}$

Ksenia Maximova ${ }^{3}$

Marie-Anne Estève ${ }^{1,2}$

Claude Villard'

Myriam Roy ${ }^{4}$

Ahmed Al-Kattan ${ }^{3}$

Marc Sentis ${ }^{3}$

Marc Gingras ${ }^{4}$

Andrei V Kabashin ${ }^{3}$

Diane Braguer ${ }^{1,2}$

'Aix Marseille Université, INSERM, CR02 UMR_S9II, Marseille, France; ${ }^{2}$ APHM, Hôpital Timone, Marseille, France; ${ }^{3} \mathrm{Aix}$ Marseille Université, CNRS, LP3 UMR 734I, Marseille, France; ${ }^{4} \mathrm{Aix}$ Marseille Université, CNRS, CINAM, UMR 7325 Marseille, France

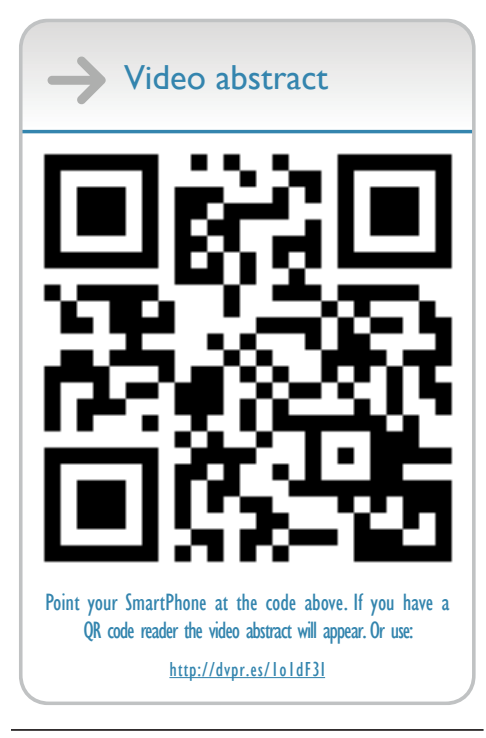

Correspondence: Diane Braguer Faculté de Pharmacie, 27 Boulevard Jean Moulin, CS 30064, I 3385 Marseille Cedex 05, France

Tel +33 0l 9l835635

Email diane.braguer@univ-amu.fr

\begin{abstract}
Due to excellent biocompatibility, chemical stability, and promising optical properties, gold nanoparticles (Au-NPs) are the focus of research and applications in nanomedicine. $\mathrm{Au}-\mathrm{NPs}$ prepared by laser ablation in aqueous biocompatible solutions present an essentially novel object that is unique in avoiding any residual toxic contaminant. This paper is conceived as the next step in development of laser-ablated Au-NPs for future in vivo applications. The aim of the study was to assess the safety, uptake, and biological behavior of laser-synthesized Au-NPs prepared in water or polymer solutions in human cell lines. Our results showed that laser ablation allows the obtaining of stable and monodisperse Au-NPs in water, polyethylene glycol, and dextran solutions. The three types of Au-NPs were internalized in human cell lines, as shown by transmission electron microscopy. Biocompatibility and safety of Au-NPs were demonstrated by analyzing cell survival and cell morphology. Furthermore, incubation of the three Au-NPs in serum-containing culture medium modified their physicochemical characteristics, such as the size and the charge. The composition of the protein corona adsorbed on $\mathrm{Au}-\mathrm{NPs}$ was investigated by mass spectrometry. Regarding composition of complement $\mathrm{C} 3$ proteins and apolipoproteins, Au-NPs prepared in dextran solution appeared as a promising drug carrier. Altogether, our results revealed the safety of laser-ablated Au-NPs in human cell lines and support their use for theranostic applications.
\end{abstract}

Keywords: protein corona, nanocarrier, cytotoxicity, green chemistry, neuroblastoma, glioblastoma

\section{Introduction}

Inorganic, organic, and hybrid nanoparticles (NPs) have been the focus of various research activities in nanomedicine, profiting from their tailor-made size, shape, surface chemistry, and physicochemical properties. ${ }^{1,2}$ They have emerged as promising candidates for the vectorization of biomolecules (as nanocarriers), for bioimaging, and as theranostic agents ${ }^{3,4}$ - in particular, in the field of oncology. ${ }^{5,6}$ Some of them provide a higher therapeutic index to anticancer drugs because of a modern "vectorization" mechanism for targeting tumors, which does not rely on membrane permeation for small molecules. ${ }^{7}$ In the passive targeting mode, this mechanism is favored by the enhanced permeability and retention effect ${ }^{8}$ that is linked to NP physical characteristics and size. In the active mode, surface chemistry (including NP biomolecular corona) can favor targeting and biocompatibility to biological surfaces and systems. In addition, the small size, large surface area-to-volume ratio, and a multiple functionalization contribute to their unique biological properties. NPs can bind, adsorb, encapsulate, 
and carry compounds such as drugs, deoxyribonucleic acid, ribonucleic acid, proteins, and biological probes with good efficiency.

Due to their chemical stability and prominent optical properties, gold nanoparticles (Au-NPs) have been at the center of attention in nanomedicine. ${ }^{9}$ These nanostructures are unique in supporting collective oscillations of free electrons (surface plasmons), which lead to a series of novel functionalities, including strong resonant absorption/ scattering, ${ }^{10}$ dramatic field enhancement, ${ }^{11,12}$ optical guidance and imaging beyond the diffraction limit, ${ }^{13}$ and ultrasensitive biosensing. ${ }^{14,15}$ Their efficient optical absorption, with typically $\sim 10^{5}$-fold higher cross-section than absorbing dyes, has been employed for light-induced hyperthermia of solid tumors. ${ }^{16-18}$ Au-NPs can also provide the contrast for cancer imaging through photoacoustic ${ }^{19}$ or light scattering, ${ }^{20}$ as well as form mobile surface-enhanced raman scattering-based tags for cancer targeting and diagnosis. ${ }^{12}$

However, conventional synthetic methods of colloidal metal nanostructures (NPs, nanorods, core-shells) are not always consistent with targeted biomedical applications. For instance, most Au-NP syntheses are dependent on a chemical reduction ${ }^{21}$ and stabilizing ligands, which generally gives rise to a surface contamination by residual anions, ligands, and reducing agents. ${ }^{22,23}$ The resulting toxicity of such nanostructures complicates their in vivo applications. ${ }^{23,24}$

In recent syntheses, Au-NPs can be prepared by laser ablation in aqueous biocompatible medium, which strongly modifies the surface chemistry and the physical and biological properties. ${ }^{25}$ In a common experimental setup, an $\mathrm{Au}$ target immersed in aqueous media is ablated by intense laser radiation, yielding a natural formation of $\mathrm{Au}$ nanoclusters. ${ }^{26}$ When released to the aqueous environment, those nanoclusters coalesce and form a colloidal solution of NPs. Laser ablation in deionized water, without stabilizing ligands and reagents, can lead to extremely stable NP solutions in a nearly monodisperse state, ${ }^{27,28}$ while the avoidance of such ligands and reagents promises a better biocompatibility. Such exceptional stability is due to an electrical repulsion effect resulting from a substantial negative charging of NPs produced. ${ }^{29}$ When chemical species are present in solution during their laser synthesis, they can interact with laser-formed nanoclusters, which stops their growth. ${ }^{30,31}$ Laser-synthesized NPs can thus exhibit unique surface chemistry, which makes them reactive with a variety of novel biocompatible materials. ${ }^{32}$ For instance, due to the presence of some higher oxidation states at high $\mathrm{pH}$, they can possess $\mathrm{O}^{-}$functionalization, making hydrogen bonding interactions possible. ${ }^{29,32}$ Au-NPs can thus be noncovalently conjugated to oligosaccharides, ${ }^{32,33}$ polymers,${ }^{34}$ proteins,${ }^{35}$ and oligonucleotides. ${ }^{36}$ Such direct conjugation (without any group ligand-specific binding) promotes those Au-NPs as novel classes of biocompatible materials for various biological applications that have been underdeveloped or not fully investigated. Additionally, the specificity of the resulting Au-NPs and their corresponding molecular hard corona formed in serum should be of high interest for biocompatibility, targeting, biological transport, and delivery. Few reports describe uptake and cytotoxicity tests of laser-synthesized Au-NPs in vitro, but not in human tumor cell lines. For example, Sobhan et $\mathrm{al}^{37}$ studied laser-synthesized Au-NPs of various sizes and their internalization into rat pancreatic tumor cells, while reporting the nontoxicity of the NPs and the size dependency in the cellular uptake. Taylor et $\mathrm{al}^{38}$ explored the cell uptake of Au-NPs in an immortalized bovine endothelial cell line. It was also shown that NP coating with cell-penetrating peptides $^{35}$ or thermoresponsive polymers ${ }^{39}$ can facilitate cell penetration without cytotoxicity. Those scarce reports are thus preliminary examples of promising in vitro applications with laser-synthesized Au-NPs.

However, for NP medical applications, protocols relevant to their future uses should first be tested. ${ }^{40}$ In particular, a dose-response effect should be performed on human cell lines. Culture and exposure conditions such as cell density, particle concentration, medium composition, time of exposure, and temperature are important for cytotoxicity. ${ }^{41}$ The biocompatibility of NPs is thus a major concern in the medical field. Indeed, NPs dispersed in a biological fluid are rapidly covered by biomolecules such as proteins, forming a molecular corona that influences NP properties and interaction with cells. ${ }^{42}$ This corona has never been investigated in laser-synthetized Au-NPs exposed to biological fluids.

This paper is conceived as the next step in the characterization and toxicological and biological assessment of the laser-synthesized Au-NPs in order to evaluate their potential for biomedical research. The presented interdisciplinary study addresses the interaction of newly laser-synthesized Au-NPs with a real biological environment appropriated to pharmacological applications. We used several Au-based nanomaterials, including ultrapure $\mathrm{Au}-\mathrm{NPs}$ in deionized water and NPs functionalized by polymers (polyethylene glycol [PEG] and dextran), in order to study the response of some biological systems to these materials, such as biocompatibility, safety, and hard corona composition. 


\section{Methods}

\section{Au-NP solutions}

NPs were prepared by femtosecond (fs) laser ablation in liquid medium. Au target (99.99\%, GoodFellow, Lille, France) was placed at the bottom of the glass vessel filled with deionized water $(18.2 \mathrm{M} \Omega \mathrm{cm})$ or with $1 \mathrm{mg} / \mathrm{mL}$ PEG (MW 20,000, Sigma-Aldrich, St Louis, MO, USA) or with $1 \mathrm{mg} / \mathrm{mL}$ dextran (MW 40,000, Sigma-Aldrich). A $2.3 \mathrm{~mm}$ diameter beam from a $\mathrm{Yb}: \mathrm{KGW}$ laser (Amplitude Systems, 1,025 nm, $480 \mathrm{fs}, 95 \mu \mathrm{J}, 1 \mathrm{kHz}$ ) was focused with a $75 \mathrm{~mm}$ lens on the surface of a target. The target was constantly moved about on the focusing plane at a speed of $0.5 \mathrm{~mm} / \mathrm{s}$, while keeping the same thickness of the liquid above the target of about $1 \mathrm{~cm}$. The ablation was performed until the solution obtained a deep red color. The concentration of the NPs was determined by the weight loss of the target after the ablation. In order to obtain the sample of Au-NPs in pure deionized water ( $\mathrm{Au}-\mathrm{NPw})$ with narrow size distribution, the NPs produced by laser ablation underwent the laser fragmentation step as it was described before. ${ }^{30,43}$ Briefly, $5 \mathrm{~mL}$ of the previously prepared solution was placed in a glass cuvette and was irradiated for 30 minutes by an fs laser beam of a $\mathrm{Yb}: \mathrm{KGW}$ laser, focused in the very middle of the cuvette, using the same focusing lens. The energy of the laser beam was varied from $10 \mu \mathrm{J}$ to $100 \mu \mathrm{J}$ in order to get the NPs with different mean sizes and narrow size distribution. The solution was stirred with a magnetic stirrer during the whole fragmentation process. Au-NPs prepared in PEG (Au-NPp) and dextran (Au-NPd) solutions and polydispersed $\mathrm{Au}-\mathrm{NPw}$ were used directly after the ablation process without a further fragmentation step.

Stock solutions were sterilized by filtration $(0.22 \mu \mathrm{m}$ pores) before storage at room temperature. For culture and experiments in living cells, NPs were freshly diluted at appropriate concentrations in complete cell culture medium.

\section{Cell culture}

Glioblastoma cell line (U87-MG) and neuroblastoma cell line (SK-N-SH) were purchased from the American Type Culture Collection (Manassas, VA, USA) and maintained in Eagle's minimal essential medium (Invitrogen, Carlsbad, CA, USA) and RPMI-1640 medium (Invitrogen), respectively, supplemented with $10 \%$ fetal bovine serum (FBS, Lonza, Basel, Switzerland), 2 mM L-glutamine, and $1 \%$ penicillin streptomycin (Lonza), namely complete cell culture medium. All cells were routinely maintained at $37^{\circ} \mathrm{C}$ and $5 \% \mathrm{CO}_{2} \cdot{ }^{44}$

\section{Transmission electron microscopy}

To determine the size of Au-NPs, small aliquots of NP solution were deposited on Formvar carbon films. After drying, copper grids were directly observed with an electron microscope (JEOL JEM 1,400; Peabody, MA, USA). The size of Au-NPs was determined from the electron micrographic images with a MegaView III Olympus (Shinjuku, Tokyo, Japan) camera managed by the Soft Images System. To evaluate cellular uptake, cells were treated for 24 hours with Au-NPw, AuNPp, and Au-NPd (1 mg/L). Then, cells were washed, fixed with $2.5 \%$ glutaraldehyde in $0.1 \mathrm{M}$ cacodylate buffer ( $\mathrm{pH} 7.2)$ for 20 minutes, and postfixed in $1 \%(\mathrm{w} / \mathrm{v})$ osmium tetroxide for 2 hours. Then, the cells were scraped and centrifuged. The pellets of cells were dehydrated in graded alcohol solution and embedded in Spurr low-viscosity medium. Ultrathin sections $(50-60 \mathrm{~nm})$ were counterstained with uranyl acetate and lead citrate before observation and analysis.

\section{Hydrodynamic diameter and zeta potential analysis}

Au-NPs without or after 1-hour incubation in complete cell culture medium were loaded into a prerinsed folded capillary cell for recording the zeta potential and dynamic light scattering (DLS) measurements. The principle employed was electrophoretic light scattering according to Smoluchowski methodology for aqueous media at $25^{\circ} \mathrm{C}$ in a Zetasizer Nano ZS instrument (Malvern Instruments, Orsay, France). A maximum of 100 subruns was performed. Results are expressed as mean \pm standard deviation from at least three independent experiments. Statistical analysis was done by using Student's $t$-test. The value of $P<0.05$ was considered statistically significant.

\section{Cell growth experiments}

Exponentially growing cells were seeded in 96-well plates for 24 hours, and then the medium was replaced with increasing Au-NP concentrations $(0-10 \mathrm{mg} / \mathrm{L})$ for 72 hours. Number of viable cells was quantified by using the colorimetric 3-(4,5dimethylthiazol-2-yl)-2,5-diphenyltetrazolium bromide (MTT, Sigma-Aldrich) assay and/or by luminescent assay (CellTiter-Glo ${ }^{\circledR}$; Promega, Madison, WI, USA) according to our previous works. ${ }^{40,45}$ At least three independent experiments (in quadruplicate) were performed, and data were expressed as mean \pm standard deviation.

\section{Visualization of the microtubular network by immunofluorescence microscopy}

U87-MG cells were seeded for 24 hours before NP or drug incubation on eight-well Chamber Slides (Lab-Tek ${ }^{\circledR}$; Thermo 
Fisher Scientific, Waltham, MA, USA). After Au-NPw or paclitaxel treatment for 6 hours, immunofluorescence staining of the microtubule network was performed using anti- $\alpha$-tubulin primary antibody (1:400, mouse monoclonal; Sigma-Aldrich) and Alexa Fluor ${ }^{\circledR} 488$-conjugated secondary antibody (1:20; Cell Signaling Technology, Beverly, MA, USA) as previously described. ${ }^{45}$ To double-label nuclei, cells were further stained with 4,6-diamidino-2-phenylindole $(0.25 \mu \mathrm{g} / \mathrm{mL}$; Sigma-Aldrich). Cells were observed using an epifluorescence microscope (Leica DM-IRBE; Wetzlar, Germany), 60× objective lens, coupled to a digital camera (CoolSNAP FX; Princeton Instruments, Trenton, NJ, USA).

\section{Measurement of reactive oxygen species}

$\mathrm{H}_{2} \mathrm{O}_{2}$ production was evaluated by $2^{\prime}, 7^{\prime}$-dichlorodihydrofluor escein diacetate (H2-DCF-DA) fluorescence (Life Technologies, Invitrogen). Cells were incubated in 96-well black plates for 6 hours or 24 hours with Au-NPw, Au-NPp, or Au-NPd at $1 \mathrm{mg} / \mathrm{L}$ and $10 \mathrm{mg} / \mathrm{L}$. After 30 minutes of $\mathrm{H}_{2}$-DCF-DA $(10 \mu \mathrm{M})$ incubation in white medium, the formation of DCF fluorescent product was measured in a Fluoroskan Ascent (Thermo Fisher Scientific) microplate fluorometer $(510 \mathrm{~nm}$ excitation, $580 \mathrm{~nm}$ emission), as previously described. ${ }^{44}$

\section{Proteomic analysis of the corona}

Au-NPs $(30 \mathrm{mg} / \mathrm{L})$ were incubated for 1 hour with complete cell culture medium at $37^{\circ} \mathrm{C}$. The NP-protein complexes were centrifuged at $20,000 \mathrm{~g}$ for 25 minutes at $4^{\circ} \mathrm{C}$. Then, complexes were washed twice with $500 \mu \mathrm{L}$ of phosphate buffered saline (PBS) at $4^{\circ} \mathrm{C}$ in order to maintain only the proteins with the highest affinity at the NP surface (hard corona). Finally, all samples were incubated in a protein denaturating buffer (Tris $50 \mathrm{nM} \mathrm{pH} \mathrm{6.8,} \mathrm{bromophenol} \mathrm{blue} 0.1 \%$, sodium dodecyl sulfate [SDS] 2\%, $\beta$-mercaptoethanol 5\%, glycerol $10 \%$ ) for 5 minutes at $95^{\circ} \mathrm{C}$, and proteins were separated by using $8 \%$ sodium dodecyl sulfate-polyacrylamide gel (SDSPAGE). Protein bands were colored with Silver ${ }^{\circledR}$ protein stain (Thermo Fisher Scientific).

For mass spectrometry analysis, gel migration was stopped after a few millimeters after concentration of the proteins. Excised gel bands containing the mixture of proteins were analyzed on an LTQ Orbitrap Velos (Thermo Fisher Scientific) coupled online to an Ultimate 3,000 nano LC system (Dionex, Sunnyvale, CA, USA). Eluting peptides were subjected to data-dependent collision-induced dissociation fragmentation. The acquired raw data were processed with Proteome Discoverer (Thermo Fisher Scientific) and submitted to the Mascot (Matrix Science) search engine.
All data were searched against the SWISS-PROT database with decoy option. The false discovery rate was calculated using the reversed database approach. Identified proteins were quantified calculating the Exponentially Modified Protein Abundance Index (emPAI). ${ }^{46}$ The emPAI value of an individual protein is applied to determine the protein content and is used to calculate ratios between the different samples for comparative analysis.

\section{Results}

\section{Laser-assisted synthesis and characterization of Au-NPs}

In our experiments we used methods of fs laser ablation in aqueous solutions, which were developed from our previous works. ${ }^{27-30,47}$ Briefly, an Au disc placed on the bottom of a glass vessel filled with aqueous solution (deionized water or solution of PEG or dextran) is illuminated by focused radiation from a $\mathrm{Yb}: \mathrm{KGW}$ laser (wavelength 1,025 nm, pulse length $480 \mathrm{fs}$, energy per pulse $95 \mu \mathrm{J}$, repetition rate $1 \mathrm{kHz}$ ), as shown in Figure 1A. The intensity of laser radiation is selected to ablate the $\mathrm{Au}$ target, and the Au nanoclusters are released into the liquid ambience, forming a colloidal NP solution. The platform with the cuvette is constantly moved to avoid the ablation from the same area on the target. The ablation process leads to a visible red coloration of the aqueous solution several seconds after the beginning of the illumination onset. NP solutions prepared by laser ablation in solutions of PEG and dextran look deep red (Figure 1B), while the solutions prepared in deionized water can additionally exhibit a slight yellow tint in the reflection, associated with a slight broadening of NP size distribution.

In order to produce quasi monosize dispersed distribution of Au-NPw, we additionally used methods of fs laser fragmentation. ${ }^{47}$ Here, Au-NPw were transferred into a glass vessel and illuminated by a focused laser beam (1,025 nm) while the deionized water solution was stirred by a magnetic stirrer. As we showed in our previous papers, ${ }^{4,78}$ in such fragmentation geometry the NPs are mainly ablated by white light supercontinuum (a broad fs length spectrum ranging from ultraviolet to infrared) generated over the path of the laser beam as a result of nonlinear self-focusing effects under the interaction of fs radiation with water. The fragmentation process led to the disappearance of yellow tints in solution color, associated with the narrowing of NP size. Thus, samples of Au-NPp and Au-NPd all looked deep red, as shown in the inset of Figure 1B, and exhibited a characteristic peak around $520 \mathrm{~nm}$ in the extinction spectra (Figure 1B), which is associated with the excitation of surface plasmons over NPs. 
A

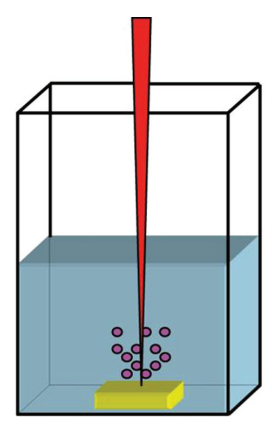

C

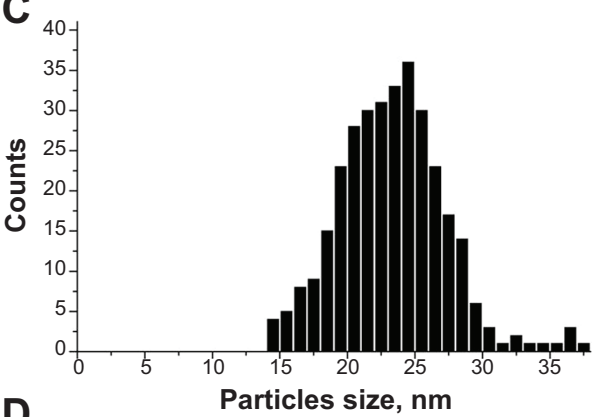

D

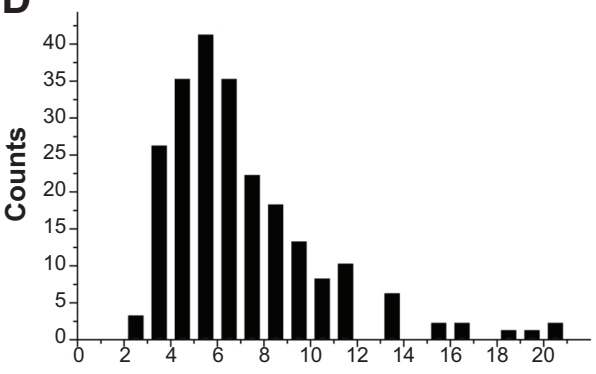

E

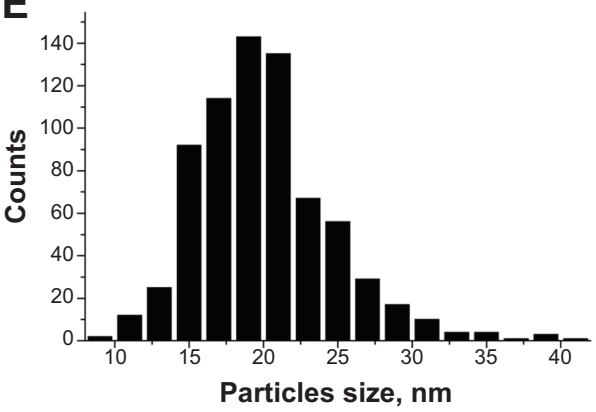

B
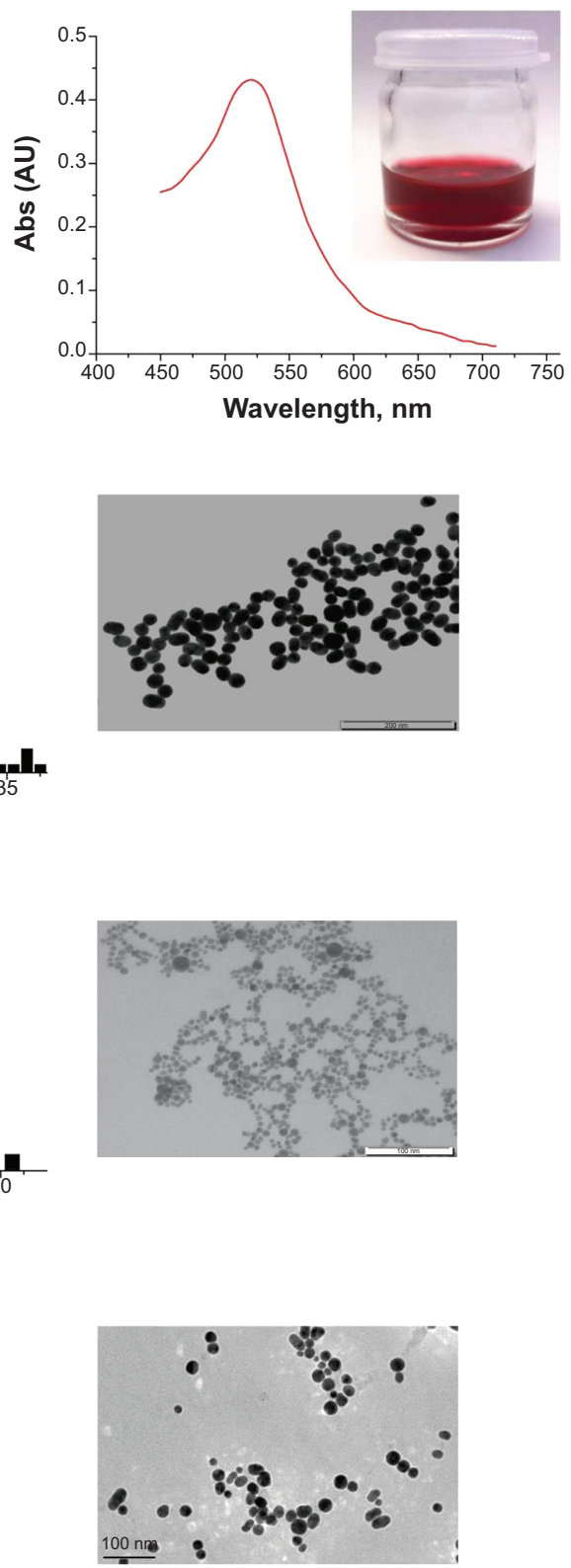

Figure I Synthesis of gold nanoparticles (Au-NPs) by laser ablation. (A) Schematics of laser ablation in aqueous solution. (B) Extinction spectrum of Au-NPs prepared by femtosecond laser ablation and further fragmentation in deionized water. The inset shows an image of a typical solution of Au-NPs. Transmission electron microscopy images and corresponding size distributions of laser-synthesized Au-NPs in deionized water (C), Au-NPs in solution of polyethylene glycol (D), and Au-NPs in solution of dextran (E).

All samples demonstrated exceptional stability, as they did not show any signs of NP precipitation after several months of storage in glass vials.

According to transmission electron microscopy (TEM) images and size distribution analysis (Figure 1C-E and Table 1), particles prepared from a PEG or a dextran solution were smaller than those produced in deionized water under identical conditions. The diameter of Au-NPw was similar when measured by TEM and DLS (20-30 nm vs $27 \pm 1 \mathrm{~nm}$,
Table 1). On the contrary, Au-NPp and Au-NPd displayed higher hydrodynamic diameter (HD) than diameter measured by TEM ( $45 \pm 5 \mathrm{~nm}$ vs $4-10 \mathrm{~nm}$ and $46 \pm 2 \mathrm{~nm}$ vs $15-25 \mathrm{~nm}$, respectively; Table 1). Furthermore, Au-NPw were negatively charged, according to their zeta potential $(-37.3 \pm 0.1 \mathrm{mV})$. Functionalizing Au-NPs with PEG and dextran significantly decreased the surface negative charge $(-28.1 \pm 0.2 \mathrm{mV}$ and $-24.8 \pm 0.5 \mathrm{mV}$, respectively; $P<0.001$ ) (Table 1). Such partial neutralization could come from residual cations 
Table I Physicochemical characterization of Au-NPs

\begin{tabular}{llll}
\hline & Au-NPw & Au-NPp & Au-NPd \\
\hline In water & & & Spherical \\
Shape (TEM) & Spherical & $4-10 \mathrm{~nm}$ & $15-25 \mathrm{~nm}$ \\
Size (TEM) & $20-30 \mathrm{~nm}$ & $45 \pm 5 \mathrm{~nm}$ & $46 \pm 2 \mathrm{~nm}$ \\
Size (DLS) & $27 \pm 1 \mathrm{~nm}$ & 0.27 & 0.20 \\
PDI & 0.26 & $-28.1 \pm 0.2 \mathrm{mV}$ & $-24.8 \pm 0.5 \mathrm{mV}$ \\
Zeta potential & $-37.3 \pm 0.1 \mathrm{mV}$ & & $86 \pm 9 \mathrm{~nm}$ \\
In complete cell culture medium & & $62 \pm 3 \mathrm{~nm}$ & 0.2 \\
Size (DLS) after I hour & $57 \pm 6 \mathrm{~nm}$ & 0.21 & $-14.5 \pm 0.6 \mathrm{mV}$ \\
PDI & 0.22 & $-12.6 \pm 1.1 \mathrm{mV}$ & \\
Zeta potential after I hour & $-13.9 \pm 3.2 \mathrm{mV}$ & \\
\hline
\end{tabular}

Abbreviations: Au-NPs, gold nanoparticles; Au-NPd, Au-NPs prepared in dextran; Au-NPp, Au-NPs prepared in polyethylene glycol; Au-NPw, Au-NPs in pure deionized water; DLS, dynamic light scattering; PDI, polydispersity index; TEM, transmission electron microscopy.

encapsulated in the polymer matrix via hydroxyl or ether functions. These observations are nevertheless indicative of a strong interaction between the polymers and NPs during their formation. Those interactions inducing an NP coating from polymers could further inhibit the seed growth, thus diminishing the mean particle size and narrowing the size distribution while ensuring the stability of NPs. ${ }^{36}$

\section{Internalization of Au-NPw, Au-NPp, and Au-NPd in human cancer cells}

After characterization of Au-NPs in solution, we studied the uptake of the three types of Au-NPs in living cells. Human cancer cells, such as SK-N-SH and U87-MG cells, were chosen according to the future use of NPs as drug delivery systems in cancer therapy. After incubation for 24 hours, Au-NPw, $\mathrm{Au}-\mathrm{NPp}$, and Au-NPd were internalized in SK-N-SH cells, as shown by using TEM (Figure 2A). Interestingly, Au-NPs entered the cells through endocytosis, as indicated by their presence in endocytotic vesicles (Figure 2Ba and b). Then, they accumulated in early and late endosomes, as well as in lysosomes, independently of solvent (Figure 2Bc and d). Moreover, $\mathrm{Au}-\mathrm{NPs}$ were never visualized inside a nucleus. Internalization was also observed in human U87-MG cells, suggesting that NP uptake is not cell type specific (Figure 2C). Furthermore, the size of Au-NPs did not influence the cellular uptake. Indeed, Au-NPw entered cells whatever the size between $6 \pm 2 \mathrm{~nm}$ and $19 \pm 4 \mathrm{~nm}$ in SK-N-SH cells (Figure S1). Altogether, these data demonstrated that the Au-NPs synthetized in water and in aqueous solutions (PEG or dextran) with size ranging from $5 \mathrm{~nm}$ to $20 \mathrm{~nm}$ can enter human cancer cells.

\section{Safety of Au-NPw, Au-NPp, and Au-NPd on human cancer cells}

Because Au-NPs enter cells, it is important to verify their safety prior to medical use. Cytotoxicity was quantified by using a colorimetric MTT assay (Figure 3A). The test is based on the reduction of the tetrazolium salt by the mitochondria of living cells. The absorbance measured at $600 \mathrm{~nm}$ is proportional to the number of living cells. As a positive control, we used paclitaxel, which is a potent cytotoxic drug candidate for loading on NPs. SK-N-SH and U87-MG cell survival was measured after 72 hours of incubation with $\mathrm{Au}-\mathrm{NPw}, \mathrm{Au}-\mathrm{NPp}$, and $\mathrm{Au}-\mathrm{NPd}$ at concentrations ranging from $0.1 \mu \mathrm{g} / \mathrm{L}$ to $10,000 \mu \mathrm{g} / \mathrm{L}$. Importantly, the three AuNPs did not show any obvious cytotoxicity (Figure 3A). On the contrary, paclitaxel was cytotoxic, as shown by the decrease of $50 \%$ SK-N-SH and U87-MG surviving cells at $24.3 \pm 7.9 \mathrm{nM}$ and 10.6 $\pm 1.4 \mathrm{nM}$, respectively (Figure 3B). Because NP color (red) may influence the readout, our results were ascertained on the two cell lines by a luminescencebased test that quantified intracellular adenosine triphosphate levels, a marker of metabolically active cells (CellTiter-Glo ${ }^{\circledR}$ assay, 72 hours) (Figure 3C). Au-NPs induced $<20 \%$ cell death at up to $10 \mathrm{mg} / \mathrm{L}$ concentration.

To confirm the safety of Au-NPw, Au-NPp, and Au-NPd, we further investigated cell morphology and the cytoskeleton structure of SK-N-SH cells. Cells treated with $1 \mathrm{mg} / \mathrm{L}$ Au-NPs for 72 hours showed the same phenotype as control cells, most cells being spread out and adherent (Figure 4A). Control cells and cells incubated with Au-NPw (1 mg/L) display classical individual microtubules irradiating from the centrosome to the cell periphery after immunofluorescence staining of tubulin (Figure 4Ba and b). In contrast, paclitaxel at $100 \mathrm{nM}$ and after 6 hours of treatment induced an unattached and round cell phenotype (Figure 4Bc). In addition, microtubule bundles and pseudoasters were detectable in cells (Figure 4B), which is typical of microtubule-stabilizing agents. ${ }^{40}$ In parallel, $\mathrm{H}_{2} \mathrm{O}_{2}$ levels were measured by the $\mathrm{H}_{2}$-DCF-DA assay. Au-NPs did not induce any increase in reactive oxygen species production in U87-MG cells (data 

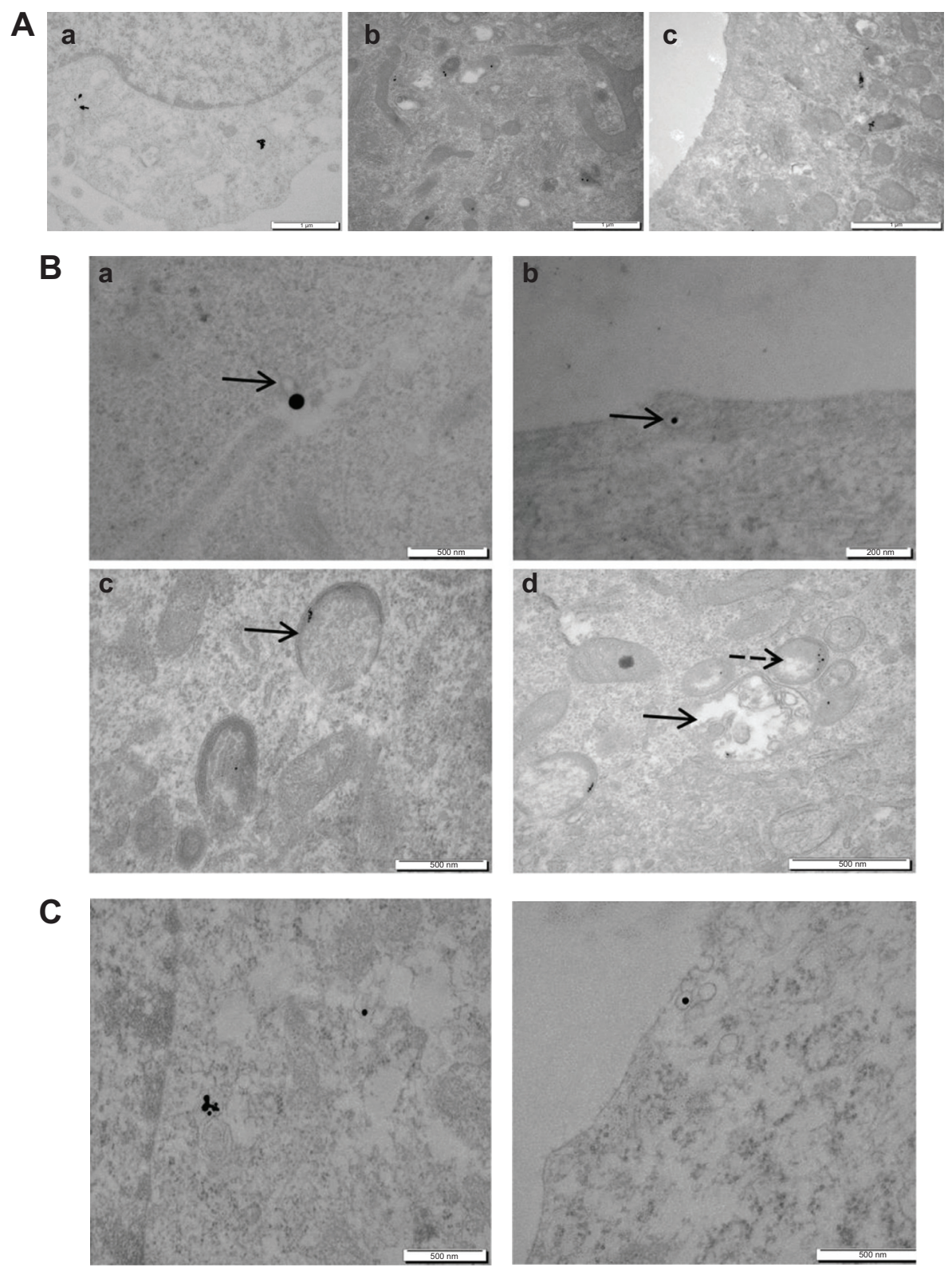

Figure 2 Uptake of Au-NPw,Au-NPp, and Au-NPd in human cancer cells. (A) Transmission electron microscopy images of neuroblastoma cell line cells incubated with I mg/L Au-NPw (a),Au-NPp (b), or Au-NPd (c) for 24 hours. (B) Intracellular trafficking of Au-NPw in neuroblastoma cell line cells. NPs are closed to the cell membrane (arrow) (a), enclosed in endocytic vesicles close to the cell membrane (arrow) (b), inside late endosome (arrow) (c), and inside endolysosome (full arrow) and lysosome (dotted arrow)

(d). (C) Transmission electron microscopy images of glioblastoma cell line cells incubated with I mg/L Au-NPw for 24 hours. Au-NPw are internalized in glioblastoma cells (left) via endocytic vesicles (right).

Abbreviations: Au-NPs, gold nanoparticles; Au-NPd,Au-NPs prepared in dextran;Au-NPp,Au-NPs prepared in polyethylene glycol;Au-NPw,Au-NPs in pure deionized water.

not shown). Altogether, our results demonstrated the safety of Au-NPs when they enter cancer cells.

\section{Biological characterization of Au-NPw, Au-NPp, and Au-NPd}

Our previous experiments have been conducted with Au-NPs incubated in complete cell culture medium containing $10 \%$ FBS. The concentration and the nature of serum were chosen according to the protocols used in pharmacological studies.
To fully characterize these promising Au-NPs in vitro, we determined their size, their charge, and the composition of the protein corona of the three types of Au-NPs in this biological medium.

\section{HD and zeta potential}

Sizes and charges of Au-NPs were measured after incubation in complete cell culture medium for 1 hour, followed by three PBS washes. Data were compared with values 
SK-N-SH cells
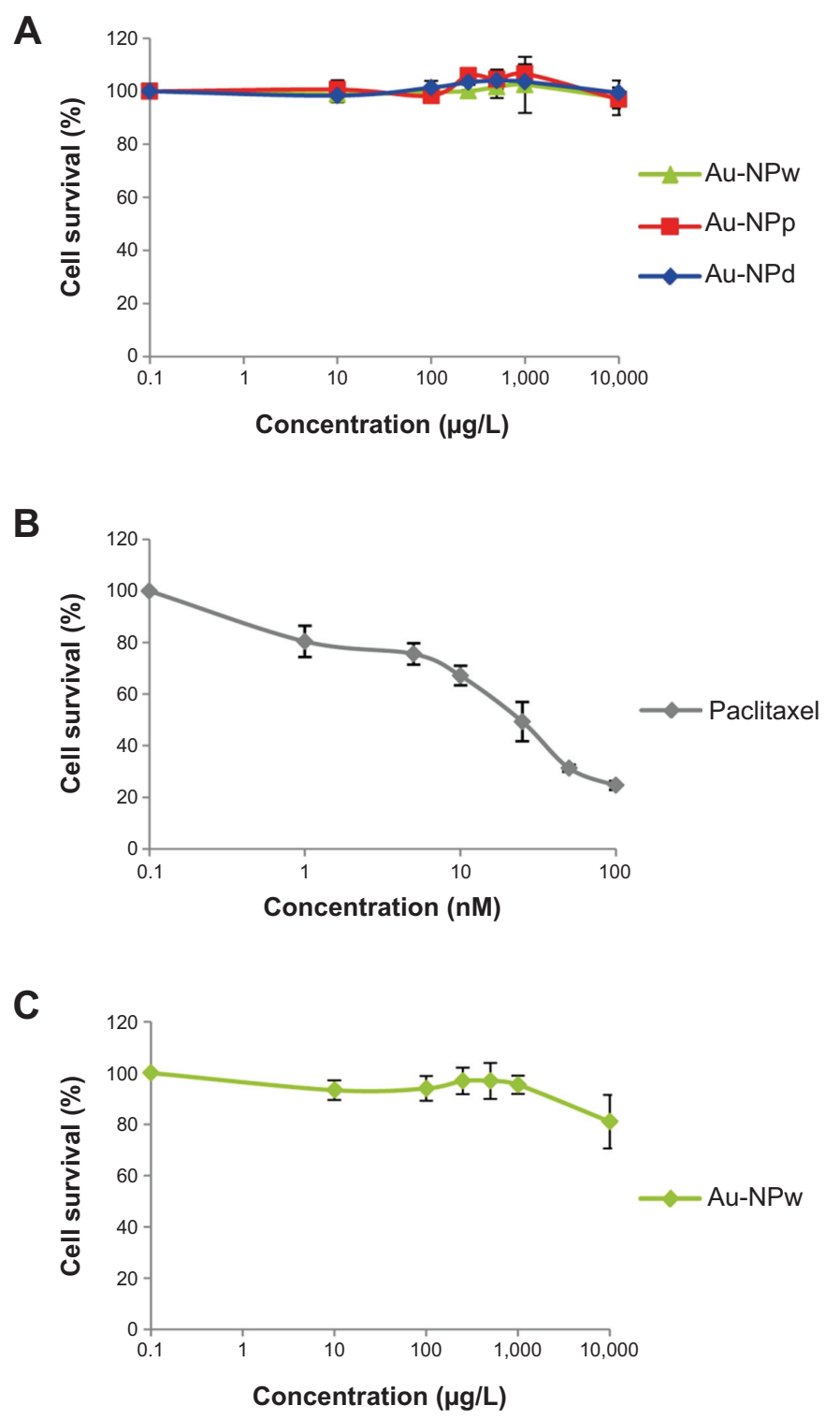

U87-MG cells
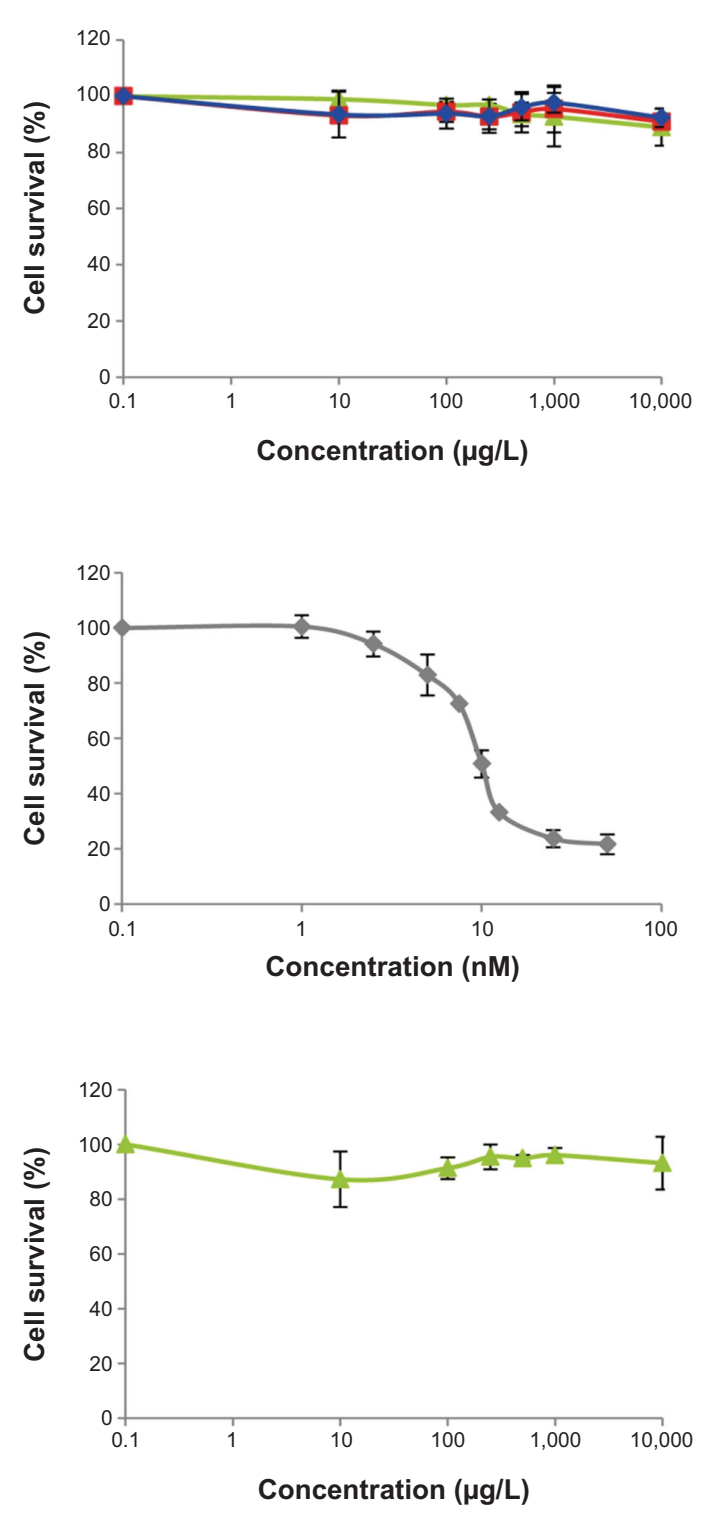

Figure 3 Safety of Au-NPs on human cancer cells. (A) MTT assay on SK-N-SH cells (left) and U87-MG cells (right) treated with Au-NPw, Au-NPp, and Au-NPd for 72 hours. (B) CellTiter-Glo ${ }^{\circledR}$ assay on SK-N-SH cells (left) and U87-MG cells (right) treated with Au-NPw for 72 hours. (C) MTT assay on SK-N-SH cells (left) and U87-MG cells (right) treated with paclitaxel as a positive control.

Abbreviations: Au-NPs, gold nanoparticles; Au-NPd, Au-NPs prepared in dextran; Au-NPp, Au-NPs prepared in polyethylene glycol; Au-NPw, Au-NPs in pure deionized water; MTT, 3-(4,5-dimethylthiazol-2-yl)-2,5-diphenyltetrazolium bromide; SK-N-SH, neuroblastoma; U87-MG, glioblastoma.

obtained at the end of Au-NP synthesis (Table 1). HD of Au-NPs was increased by 1.3- to 2.1-fold, due to the formation of hard protein corona. Au-NPd showed the largest HD ( $86 \pm 9 \mathrm{~nm}$ ), whereas the HD of Au-NPw and Au-NPp was around $60 \mathrm{~nm}(57 \pm 6 \mathrm{~nm}$ and $62 \pm 3 \mathrm{~nm}$, respectively). This statistically significant difference $(P<0.05)$ suggested that Au-NPd bound a higher number of proteins or larger proteins. The surface charge of the three Au-NPs became less negative after incubation in biological medium, with values between $-12.6 \pm 1.1 \mathrm{mV}$ and $-14.5 \pm 0.6 \mathrm{mV}(P<0.001)$.
These data indicated that proteins bound to the Au surface of NPs to reduce their free energy and to realize a neutralizing effect.

\section{Formation of protein corona and its composition on Au-NPs}

Protein composition of the corona of the three Au-NPs was analyzed by electrophoresis and mass spectrometry. SDS-PAGE results indicated that a protein corona was formed at 30 minutes of incubation and it did not distinctly 
A
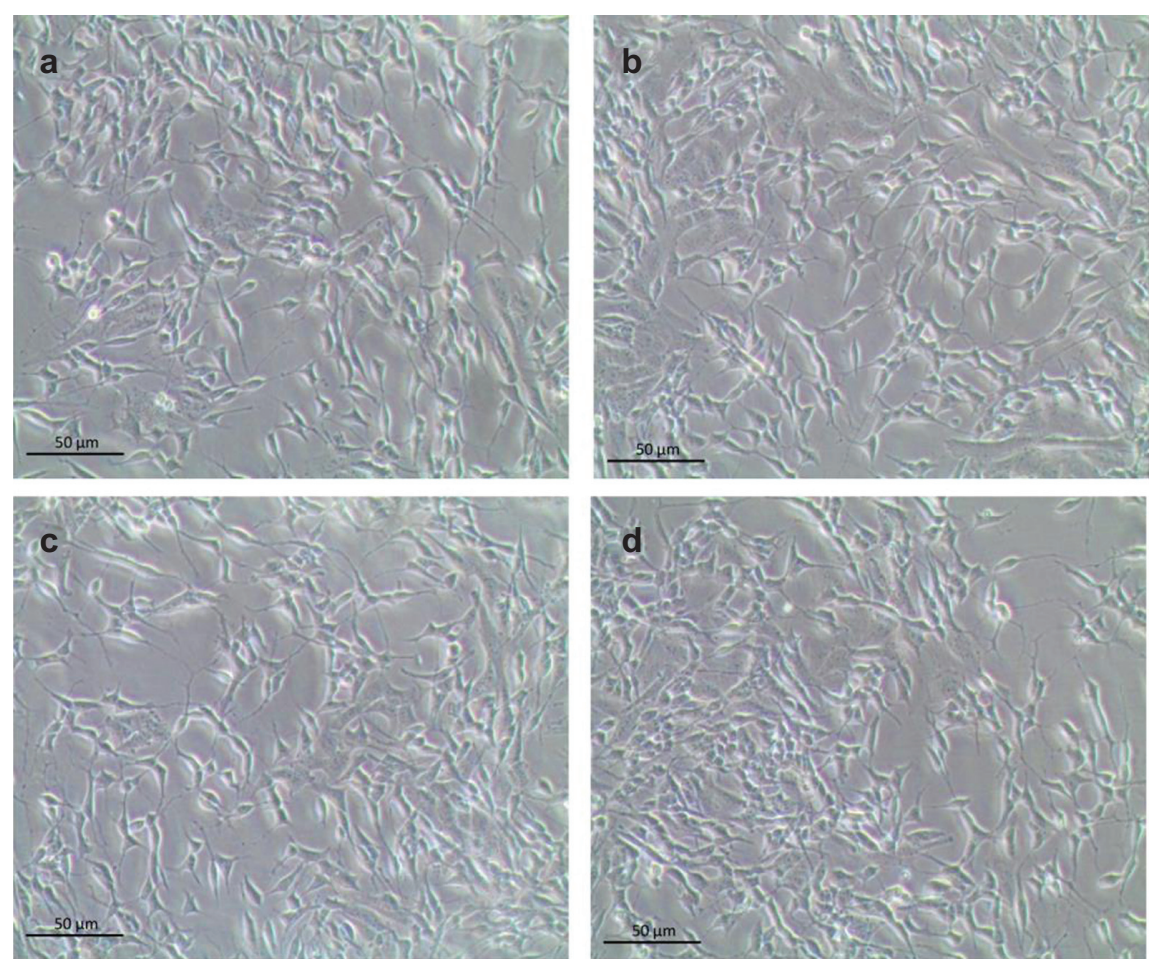

B

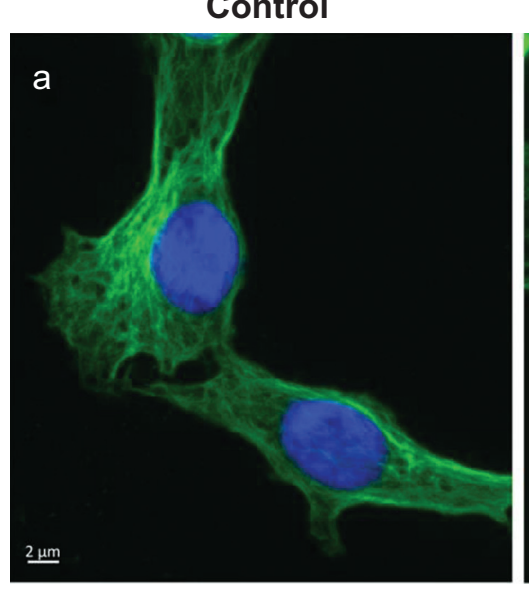

Au-NPw $1 \mathrm{mg} / \mathrm{L}$

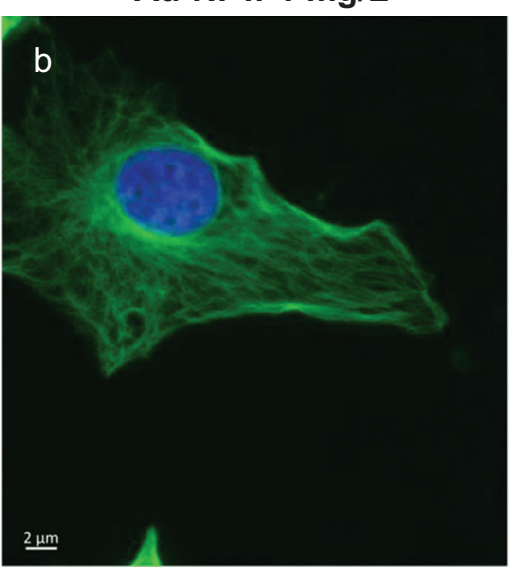

Paclitaxel $100 \mathrm{nM}$

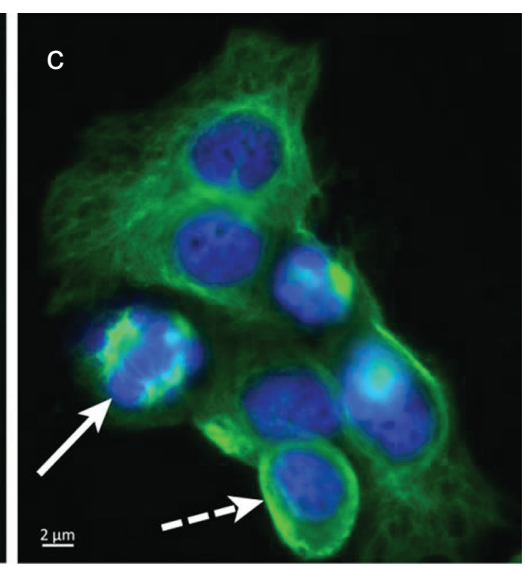

Figure 4 Morphology of cancer cells after Au-NP incubation for 6 hours at I mg/L. (A) Phase-contrast microscopy (I0x) of neuroblastoma cells control (a) or treated with Au-NPw (b), Au-NPp (c), or Au-NPd (d) at I mg/L. (B) Immunofluorescence imaging of microtubular network in glioblastoma cells control (a), incubated for 6 hours with Au-NPw at I mg/L (b) or paclitaxel at $100 \mathrm{nM}$ (c). Full arrow and dotted arrow show pseudoaster and bundles, respectively.

Abbreviations: Au-NPs, gold nanoparticles; Au-NPd, Au-NPs prepared in dextran; Au-NPp, Au-NPs prepared in polyethylene glycol; Au-NPw, Au-NPs in pure deionized water.

change after 1-hour and 24-hour incubation (Figure 5A). Indeed, the amount and profile of proteins look similar, as shown by ImageJ software analysis (Figure 5B). In order to anticipate their future uses as nanocarriers, we identify the proteins of corona formed on each Au-NP. NanoLCESI-Orbitrap analysis and identification of proteins from the Mascot algorithm showed some differences between Au-NPs (Table S1). About 100 different proteins were adsorbed on Au-NPd, against 80 for Au-NPw and Au-NPp
(Figure 5C). Moreover, more serum albumin $(25 \%$ of the total of proteins for $\mathrm{Au}-\mathrm{NPd}$ vs $10 \%$ for $\mathrm{Au}-\mathrm{NPw}$ and Au-NPp) and apolipoproteins (Apos) A-I and A-II (particularly ApoA-I: 4.29 vs 1.3 and 2.49, respectively) and less complement $\mathrm{C} 3$ protein (0.95 vs 1.94 and 1.66, respectively) were adsorbed on Au-NPd (Figure 5C). Coagulation proteins (eg, fibrinogen, antithrombin III, coagulation factor VIII, hemoglobin) were found on the three types of Au-NPs (Table S1). 
A

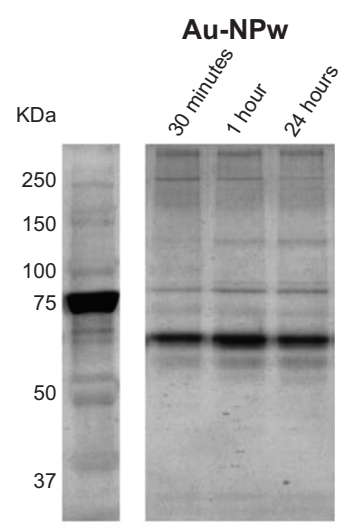

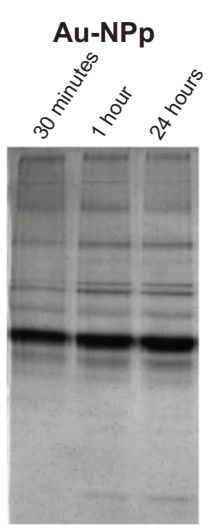

Au-NPd

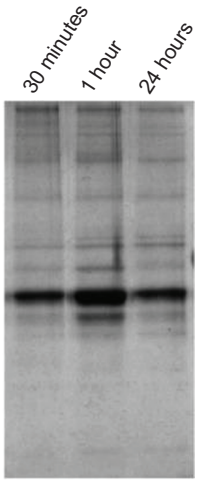

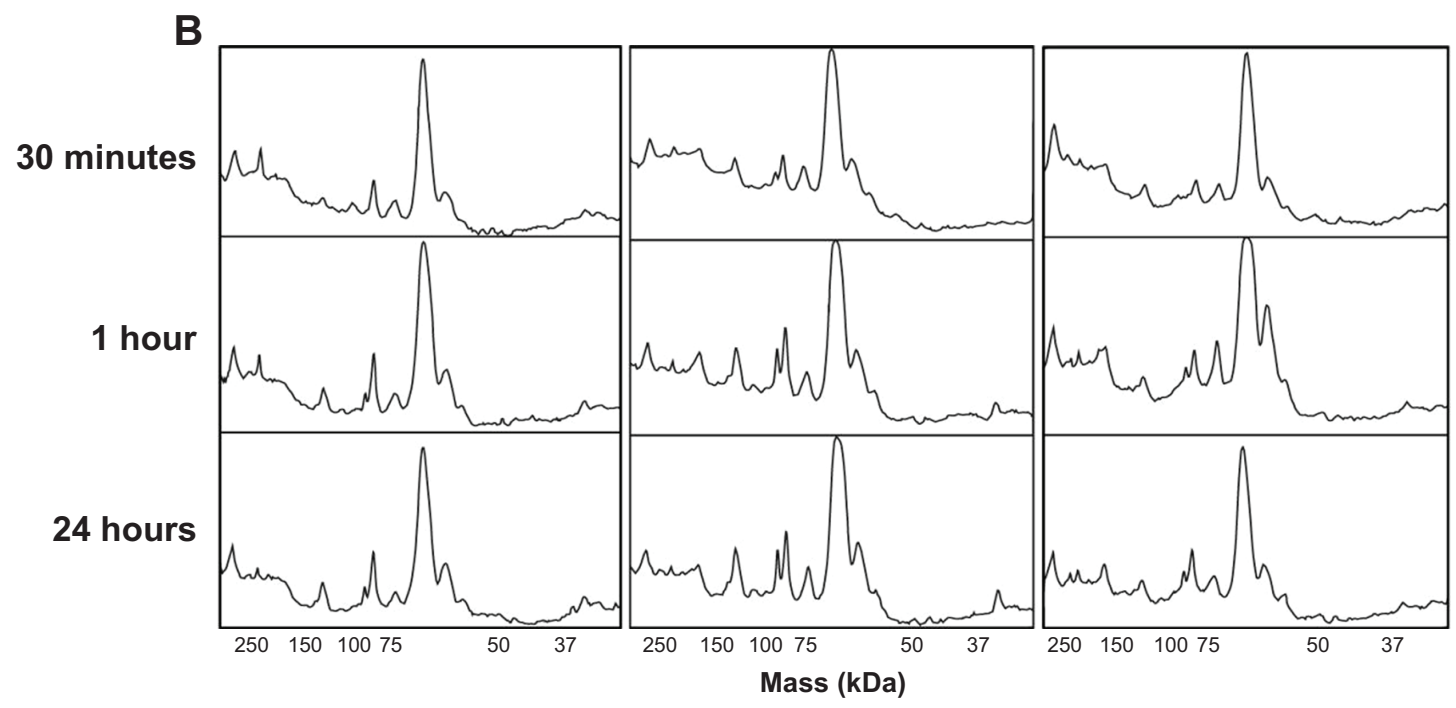

C
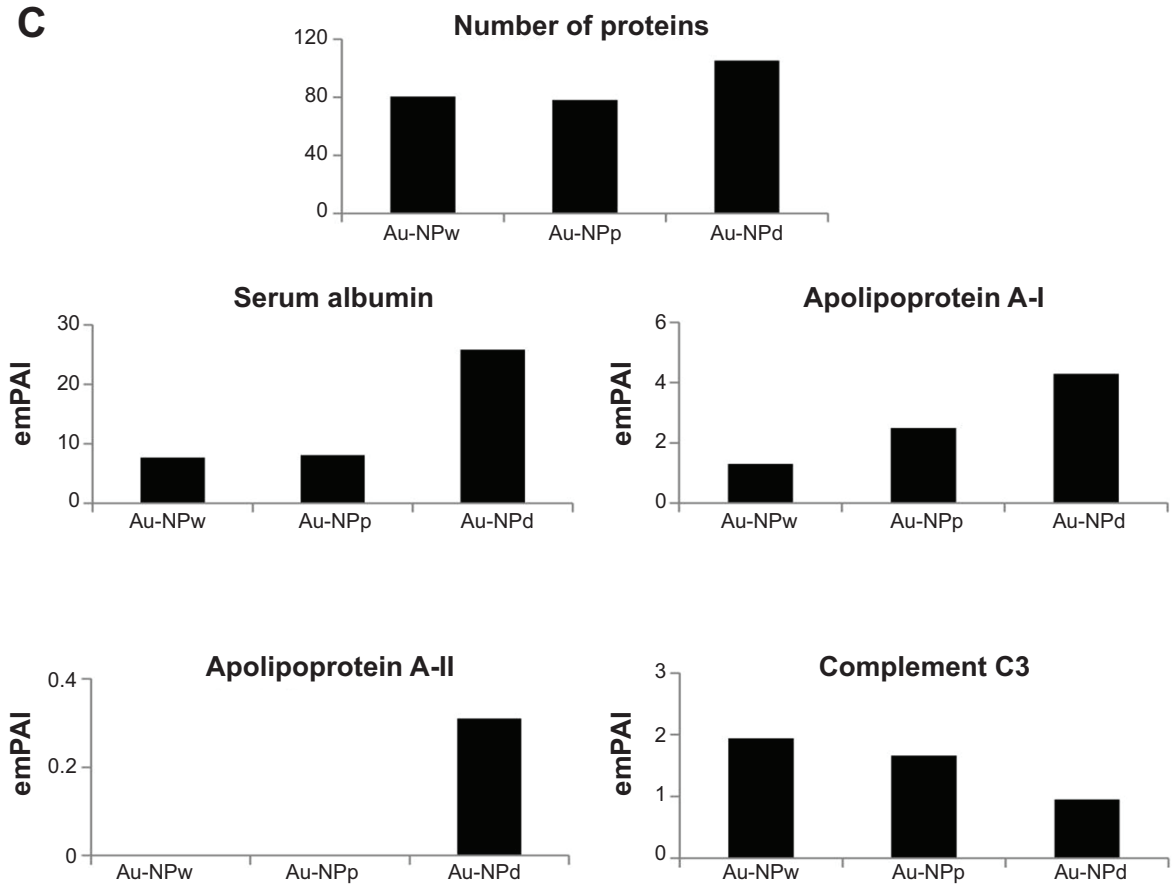

Figure 5 Time evolution and composition of protein corona. (A) Sodium dodecyl sulfate-polyacrylamide gel of corona protein on Au-NPw, Au-NPp, and Au-NPd at 30 minutes, I hour, and 24 hours. Left lane: protein molecular weight markers. (B) Image profile of protein corona formed on each Au-NP at 30 minutes, I hour, and 24 hours. (C) Histograms representing the expression of C3 complement proteins and apolipoproteins (A-I, A-II, and E) adsorbed on Au-NPw, Au-NPp, and Au-NPd.

Abbreviations: Au-NPs, gold nanoparticles; Au-NPd, Au-NPs prepared in dextran; Au-NPp, Au-NPs prepared in polyethylene glycol; Au-NPw, Au-NPs in pure deionized water; emPAl, Exponentially Modified Protein Abundance Index. 


\section{Discussion}

Here we have reported a detailed analysis of safety and biocompatibility of three spherical Au-NPs synthetized by fs laser ablation. This technique has the advantage of generating NPs while avoiding a contamination from NP-stabilizing ligands or remains from chemical reagents, which are often toxic to cells. The NP surface or coating is thus different according to the solvents and additives used during synthesis: water, PEG, and dextran solutions. PEG and dextran are additives with some advantages in drug delivery. In fact, PEGylation of NPs not only provides the required biocompatibility (as it is often observed in the PEGylation of proteins), a higher stability, and solubility in aqueous medium but also increases the circulation time of NPs in the blood stream for improving a targeted delivery without any systemic toxicity. ${ }^{49}$ The PEG chains added to NPs to improve their biocompatibility can also be functionalized, thus behaving as linkers to some tumor-specific ligands, toward a better targeting to cancer tissues and cells. With dextran as a drug carrier, the same advantages were reported..$^{50}$

In this work, it is the first time that biological safety and identity of laser-ablated Au-NPs have been determined according to the conditions of pharmacological applications: human cell lines, $37^{\circ} \mathrm{C}, 5 \% \mathrm{CO}_{2}, 10 \% \mathrm{FBS}$, cell viability assay for 72 hours. We have shown the safety of Au-NPw, $\mathrm{Au}-\mathrm{NPp}$, and Au-NPd on neuroblastoma and glioblastoma cells by using complementary experiments. Indeed, we failed to determine the concentration of Au-NPs that inhibited 50\% of cell growth. Au-NPs at $10 \mathrm{mg} / \mathrm{L}$ induced only a $20 \%$ decrease in living cells after a 3-day incubation. At this high concentration, a decrease may reflect interference between Au-NPs and dye reagents rather than a cell death induction. ${ }^{51}$ In fact, the conflicting results observed in literature on Au-NP toxicity may be due to the lack of normalized protocols, emphasizing the need to establish standards in nanotoxicology. In addition, cell morphology, cell cytoskeleton, and reactive oxygen species levels were unmodified by Au-NP exposure, indicating that cell proliferation and motility were not altered. Each Au-NP was internalized in SK-N-SH and U87-MG cells in a polymer-independent manner. Uptake of Au-NPs involved endocytosis, as described in literature. ${ }^{52} \mathrm{In}$ addition, SK-N-SH cells overexpress glycoprotein-P (P-gp), which is an efflux pump involved in resistance mechanisms to chemotherapy and in physiological barriers such as the blood-brain barrier. ${ }^{53}$ As Au-NPs enter SK-N-SH cells, they could be used as a drug carrier to reverse drug resistance and to increase efficacy of anticancer drugs, allowing them to reach organs protected by a barrier. ${ }^{54}$ Indeed, the nanosize and the specific surface biochemistry of NPs might counteract the P-gp functions when compared with usual smaller biomolecules or drugs. However, when NPs are incubated in biological fluid such as cell culture medium containing serum, proteins bind to the NP surface to make a protein corona. The latter has been shown to reduce internalization of Au-NPs, which may explain the low intracellular amount of Au-NPs observed. ${ }^{55}$ The corona is formed in only 30 seconds after incubation in a biological medium, suggesting that it plays a role in the toxicity profile of Au-NPs ${ }^{56}$ In this study, we characterized the hard corona that remains on NPs after PBS washes. Formation of the corona is confirmed by the increase in the HD of Au-NPs. The sizes of Au-NPw, Au$\mathrm{NPd}$, and Au-NPp remained $<100 \mathrm{~nm}$.

Some water inclusion responsible for maintaining the protein structure, combined to the surrounding solvation layers, should contribute to those values. It is expected that an important binding mode of proteins to Au-NPs should come from some sulfur-Au interactions (via disulfide or thiol functions from proteins). The latter binding forces to Au-NPs are well known in nanoscience. In passive delivery, NPs are thus able to exploit the unique enhanced permeability and retention effects that enable them to leave the systemic circulation and to enter the extravascular space, where they can accumulate around and within tumor cells. ${ }^{57}$ Moreover, protein corona modifies the physicochemical characteristics of the NPs, as shown by the neutralizing effect on surface charge, but also changes the balance of lipophilicity and water solubility according to the bound proteins. The zeta potential remains negative, which is consistent with the low toxicity of Au-NPs. ${ }^{58}$ This observation confirms the need to measure NP charge in biological fluids before in vivo study. ${ }^{59}$ The protein composition of the corona is relatively stable in time in the same medium, with few differences between 30 minutes and 24 hours of incubation.

Furthermore, we performed an in-depth analysis by mass spectrometry, which indicated some specific features for each Au-NP. Albumin is the most abundant protein on each Au-NP. Interestingly, it is known to be a hydrophobic protein that could facilitate the stability of a hydrophobic drug-NP complex via some supramolecular forces (weak molecular interactions) or encapsulation at the NP surface. Moreover, albumin is able to promote prolonged circulation time in blood ${ }^{60}$ Recently, $\mathrm{N}$-albumin-bound paclitaxel was approved by the US Food and Drug Administration for clinical treatment of breast and pancreatic cancers. It is the first albumin NP used in cancer therapy. In addition to albumin binding, Au-NPs generated by fs laser ablation also 
bound Apos. These proteins are often involved in intracellular trafficking and they allow transport across biological barriers. ApoE or ApoA-I bound to an NP enables their interaction with some brain endothelial cells. ${ }^{61}$ In clinical assays, only a few anticancer drugs are able to cross the blood-brain barrier. As Au-NPs enter glioblastoma cells and bind to Apos, we suggest that Au-NPs could be good anticancer drug carrier candidates for brain tumor treatment. Au-NPs generated from fs laser ablation also bind immune proteins. It seems that Au-NPd bind less C3 complement protein than Au-NPw or Au-NPp. Binding complement factors are known to promote opsonization (internalization of particles or pathogens, displaying surface complement proteins, by phagocytic cells) but also the eventual removal of particles from the systemic circulation via the cells from the reticuloendothelial system. NPs tend to be sequestered in the reticuloendothelial system organs very rapidly and concentrate in the liver and spleen. We could suppose that Kupffer cells would have less affinity for Au-NPd that could limit hepatic accumulation of $\mathrm{Au}$ in vivo and subsequent liver toxicity. ${ }^{62}$ Moreover, more albumin and Apos were adsorbed at the surface of Au-NPd, suggesting that Au-NPd are the most promising NPs. These promising results open the way to investigate the safety of Au-NPs in healthy and tumor-bearing animals before binding Au-NPs to anticancer drugs. Furthermore, cell targeting could be enhanced by functionalizing Au-NPs with antibodies or cell-penetrating peptides when taking into account the roles that protein corona could play. In a more general concept, our results provide further thoughts about the evaluation of Au-NP toxicity, cell targeting, and delivery of NP-drug conjugates to fight cancer in a nanomedicinal approach.

\section{Conclusion}

Taken together, our results showed that Au-NPs prepared by fs laser ablation in aqueous solution were biocompatible and safe. Au-NPs were synthesized and functionalized using the performance and advantages of fs laser ablation, avoiding contamination by some undesired chemicals that could interfere with biological studies. We demonstrated the internalization through endocytosis of Au-NPs in two malignant human cell lines, independently of synthesis solutions and/ or size. After exposure of NPs to serum-containing medium, corona proteins assembled, probably playing a major role in biocompatibility/toxicity and transport across physiological barriers of Au-NPs. This chemical, physico-optical and pharmacological interdisciplinary approach and the convergence of the methods used allowed us to better understand the basic identity, biological behavior, and properties of functionalized NPs under pharmacological conditions. To conclude, a better vectorization of anticancer drugs could take advantage of binding to Au-NPs, surrounded by their protein corona. Au-NPs could thus be effective nanocarriers for diagnosis agents and as drug conjugates (theranostic).

\section{Acknowledgments}

This work has been carried out thanks to the support of the French National Research Agency (ANR) Lasernanobio 10Blan 919 03, DGOS (SIRIC label) INCa-DGOS-Inserm 6038, and A*MIDEX project (No. ANR-11-IDEX-0001-02) funded by the "Investissements d'Avenir" French Government program, managed by the ANR. Transmission electron microscopy analysis, in solution and in cells, was performed in the Department of Electron Microscopy (health campus Timone) under the supervision of Joël Courageot. The MS analyses were carried out in the Proteomic Platform (PIT2) of UMR INSERM 911 (MaP platform). The authors wish to thank Nathalie Ferté for preparation of samples and preliminary DLS measurements at CINaM and Caroline Orneto (Laboratory of Industrial Galenic Pharmacy and Cosmetology, Faculty of Pharmacy) for help in the DLS and zeta potential measurements.

\section{Disclosure}

The authors report no conflicts of interest in this work.

\section{References}

1. Kim BY, Rutka JT, Chan WC. Nanomedicine. $N$ Engl J Med. 2010;363(25):2434-2443.

2. Riehemann K, Schneider SW, Luger TA, Godin B, Ferrari M, Fuchs H. Nanomedicine: challenge and perspectives. Angew Chem Int Ed. 2010;48(5):872-897.

3. De M, Ghosh PS, Rotello VM. Applications of nanoparticles in biology. Adv Mater. 2008;20(22):4225-4241.

4. Gingras M, Roy M. Dendrimer-based drug delivery systems: from theory to practice. In: Cheng Y, editor. Degradable Dendrimers for Drug Delivery. New York, NY: John Wiley and Sons; 2012:239-303.

5. Thakor AS, Gambhir SS. Nanooncology. The future of cancer diagnosis and therapy. CA Cancer J Clin. 2013;63(6):395-418.

6. Llevot A, Astruc D. Applications of vectorized gold nanoparticles to the diagnosis and therapy of cancer. Chem Soc Rev. 2012;41(1): 242-257.

7. Wang J, Byrne JD, Napier ME, DeSimone JM. More effective nanomedicines through particle design. Small. 2011;7(14):1919-1931.

8. Maeda $H$. The enhanced permeability and retention effect in tumor vasculature: the key role of tumor-selective macromolecular drug targeting. Drug Targeting Adv Enzyme Regul. 2001;41(1):189-207.

9. Khlebtsov N, Dykman L. Biodistribution and toxicity of engineered gold nanoparticles: a review of in vitro and in vivo studies. Chem Soc Rev. 2011;40(3):1647-1671.

10. Jain PK, Lee KS, El-Sayed IH, El-Sayed MA. Calculated absorption and scattering properties of gold nanoparticles of different size, shape, and composition: applications in biological imaging and biomedicine. J Phys Chem B. 2006;110(14):7238-7248. 
11. Nie S, Emory SR. Probing single molecules and single nanoparticles by surface-enhanced Raman scattering. Science. 1997;275(5303): 1102-1106.

12. Qian XM, Peng XH, Ansari DO, et al. In vivo tumor targeting and spectroscopic detection with surface-enhanced Raman nanoparticle tags. Nature Biotech. 2008;26(1):83-90.

13. Lal S, Link S, Halas NJ. Nano-optics from sensing to waveguiding. Nature Photon. 2007;26(1):641-648.

14. Kabashin AV, Evans P, Patskovsky S, et al. Plasmonics nanorod metamaterials for biosensing. Nature Mater. 2009;8(11):867-871.

15. Kravets VG, Schedin F, Jalil R, et al. Singular phase nano-optics in plasmonic metamaterials for label-free single-molecule detection. Nature Mater. 2013;12(4):304-309.

16. Hirsch LR, Stafford RJ, Bankson JA, et al. Nanoshell-mediated nearinfrared thermal therapy of tumors under magnetic resonance guidance. Proc Nat Acad Sci. 2003;100(23):13549-13554.

17. Huang X, El-Sayed IH, Qian W, El-Sayed MA. Cancer cell imaging and photothermal therapy in near-infrared region by using gold nanorods J Am Chem Soc. 2006;128(6):2115-2120.

18. Gobin AM, Lee MH, Halas NJ, James WD, Drezek RA, West JL. Near-infrared resonant nanoshells for combined optical imaging and photothermal cancer therapy. Nano Lett. 2007;7(7):1929-1934.

19. Wang Y, Xie X, Wang X, et al. Photoacoustic tomography of a nanoshell contrast agent in the in vivo rat brain. Nano Lett. 2004;4(9): 1689-1692.

20. Sokolov K, Follen M, Aaron J, et al. Real-time vital optical imaging of precancer using anti-epidermal growth factor receptor antibodies conjugated to gold nanoparticles. Cancer Res. 2003;63(9):1999-2004.

21. Hayat MA. Colloidal Gold: Principles, Methods, and Applications. San Diego, CA: Academic Press; 1989.

22. Huang HZ, Yang XR. Synthesis of polysaccharide-stabilized gold and silver nanoparticles: a green method. Carbohyd Res. 2004;339(15): 2627-2631.

23. Mukherjee P, Ahmad A, Mandal D, et al. Fungus-mediated synthesis of silver nanoparticles and their immobilization in the mycelial matrix: a novel biological approach to nanoparticle synthesis. Nano Lett. 2001; 1(10):515-519.

24. James WD, Hirsch LR, West JL, O’Neal PD, Payne JD. Application of INAA to the build-up and clearance of gold nanoshells in clinical studies in mice. J Radioanal Nucl Chem. 2007;271(2):455-459.

25. Kabashin AV, Delaporte P, Perreira A, et al. Nanofabrication with pulsed lasers. Nanoscale Res Lett. 2010;5(3):454-463.

26. Nedderson J, Chumanov G, Cotton TM. Laser ablation of metals: a new method for preparing SERS active colloids. Appl Spectrosc. 1993; 47(12):1959-1964

27. Kabashin AV, Meunier M. Synthesis of colloidal nanoparticles during femtosecond laser ablation of gold in water. J Appl Phys. 2003;94(12): 7941-7943.

28. Kabashin AV, Meunier M. Femtosecond laser ablation in aqueous solutions: a novel method to synthesize non-toxic metal colloids with controllable size. J Phys Conf Series. 2006;59(1):354-357.

29. Sylvestre JP, Poulin S, Kabashin AV, Sacher E, Meunier M, Luong JHT. Surface chemistry of gold nanoparticles produced by laser ablation in aqueous media. J Phys Chem B. 2004;108(43):16864-16869.

30. Mafuné F, Kohno JY, Takeda Y, Kondow T. Formation and size control of silver nanoparticles by laser ablation in aqueous solution. $J$ Phys Chem B. 2000;104(39):9111-9117.

31. Mafuné F, Kohno JY, Takeda Y, et al. Formation of gold nanoparticles by laser ablation in aqueous solution of surfactant. J Phys Chem B. 2001; 105(22):5114-5120.

32. Sylvestre JP, Kabashin AV, Sacher E, Meunier M, Luong JHT. Stabilization and size control of gold nanoparticles during laser ablation in aqueous cyclodextrins. J Am Chem Soc. 2004;126(23):7176-7177.

33. Kabashin AV, Meunier M, Kingston C, Luong JHT. Fabrication and characterization of gold nanoparticles by femtosecond laser ablation in aqueous solution of cyclodextrins. J Phys Chem B. 2003;107(19): 4527-4531.
34. Besner S, Kabashin AV, Meunier M, Winnik FM. Synthesis of size-tunable polymer-protected gold nanoparticles by femtosecond laser-based ablation and seed growth. J Phys Chem C. 2009;113(22):9526-9531.

35. Petersen S, Barchanski A, Taylor U, Klein S, Rath D, Barcikowski S. Penetratin-conjugated gold nanoparticles: design of cell-penetrating nanomarkers by femtosecond laser ablation. J Phys Chem C. 2011; 115(12):5152-5159.

36. Petersen $\mathrm{S}$, Barcikowski S. In situ bioconjugation: single step approach to tailored nanoparticle-bioconjugates by ultrashort pulsed laser ablation. Adv Funct Mater. 2009;19(8):1167-1172.

37. Sobhan MA, Sreenivasan VKA, Withford MJ, et al. Non-specific internalization of laser ablated pure gold nanoparticles in pancreatic tumour cell. Colloid Surface B. 2012;92(1):190-195.

38. Taylor U, Klein S, Petersen S, Kues W, Barcikowski S, Rath D. Nonendosomal cellular uptake of ligand-free, positively charged gold nanoparticles. Cytom Part A. 2010;77(5):439-446.

39. Salmaso S, Caliceti P, Amendola V, et al. Cell up-take control of gold nanoparticles functionalized with a thermoresponsive polymer. J Mater Chem. 2009;19(11):1608-1615.

40. Pagano A, Honoré S, Estève MA, Braguer D. Nanodrug potential in cancer therapy: efficacy/toxicity studies in cancer cells. Int J Nanotechnol. 2012;9(3):3-7.

41. Bouwmeester H, Lynch I, Marvin HJ, et al. Minimal analytical characterization of engineered nanomaterials needed for hazard assessment in biological matrices. Nanotoxicology. 2011;5(1):1-11.

42. Lesniak A, Fenaroli F, Monopoli MP, Åberg C, Dawson KA, Salvati A. Effects of the presence or absence of a protein corona on silica nanoparticle uptake and impact on cells. ACS Nano. 2012;6(7):5845-5857.

43. Liu W, Kosareva O, Golubtsov IS, et al. Femtosecond laser pulse filamentation versus optical breakdown in $\mathrm{H}_{2} \mathrm{O}$. Appl Phys B. 2003;76(3): 215-229.

44. Khawaja NR, Carré M, Kovacic H, Estève MA, Braguer D. Patupiloneinduced apoptosis is mediated by mitochondrial reactive oxygen species through Bim relocalization to mitochondria. Mol Pharmacol. 2008; 74(4):1072-1083.

45. Estève MA, Carré M, Bourgarel-Rey V, et al. Bcl-2 down-regulation and tubulin subtype composition are involved in resistance of ovarian cancer cells to vinflunine. Mol Cancer Ther. 2006;5(11):2824-2833.

46. Ishihama Y, Oda Y, Tabata T, et al. Exponentially Modified Protein Abundance Index (emPAI) for estimation of absolute protein amount in proteomics by the number of sequenced peptides per protein. $\mathrm{Mol}$ Cell Proteomics. 2005;4(9):1265-1272.

47. Besner S, Kabashin AV, Meunier M. Two-step femtosecond laser ablation-based method for the synthesis of stable and ultra-pure gold nanoparticles in water. Appl Phys A. 2007;88(2):269-272.

48. Kubiliute R, Maximova K, Lajevardipour A, et al. Ultra-pure, waterdispersed Au nanoparticles produced by fs laser ablation and fragmentation. Int J Nanomedicine. 2013;8(1):2601-2611.

49. Ajay SK, Soumen D, Suntharampillai T, Sudipta S. PEGylated inorganic nanoparticles. Angew Chem Int Ed Engl. 2011;50(9):1980-1994.

50. Varshosaz J. Dextran conjugates in drug delivery. Expert Opin Drug Deliv. 2012;9(5):509-523.

51. Vetten MA, Tlotleng N, Tanner Rascher D, et al. Label-free in vitro toxicity and uptake assessment of citrate stabilised gold nanoparticles in three cell lines. Part Fibre Toxicol. 2013;10(1):50.

52. Chithrani BD, Stewart J, Allen C, Jaffray DA. Intracellular uptake, transport, and processing of nanostructures in cancer cells. Nanomedicine. 2009;5(2):118-127.

53. Agarwal S, Hartz AM, Elmquist WF, Bauer B. Breast cancer resistance protein and P-glycoprotein in brain cancer: two gatekeepers team up. Curr Pharm Des. 2011;17(26):2793-2802.

54. Shapira A, Livney YD, Broxterman HJ, Assaraf YG. Nanomedicine for targeted cancer therapy: towards the overcoming of drug resistance. Drug Resist Updat. 2011;14(3):150-163.

55. Treuel L, Brandholt S, Maffre P, Wiegele S, Shang L, Nienhaus GU. Impact of protein modification on the protein corona on nanoparticles and nanoparticle-cell interactions. ACS Nano. 2014;8(1):503-513. 
56. Tenzer S, Docter D, Kuharev J, et al. Rapid formation of plasma protein corona critically affects nanoparticle pathophysiology. Nat Nanotechnol. 2013;8(10):772-781.

57. Perrault SD, Walkey C, Jennings T, Fischer HC, Chan WC. Mediating tumor targeting efficiency of nanoparticles through design. Nano Lett. 2009;9(5):1909-1915.

58. Goodman CM, McCusker CD, Yilmaz T, Rotello VM. Toxicity of gold nanoparticles functionalized with cationic and anionic side chains bioconjugate. Bioconjug Chem. 2004;15(4):897-900.

59. Townson JL, Lin YS, Agola JO, et al. Differing in vivo characteristics of size- and charge-matched mesoporous silica nanoparticles. J Am Chem Soc. 2013;135(43):16030-16033.
60. Ogawara K, Furumoto K, Nagayama S, et al. Precoating with serum albumin reduces receptor-mediated hepatic disposition of polystyrene nanosphere: implications for rational design of nanoparticles. J Control Release. 2004;100(3):451-455.

61. Kreuter J, Shamenkov D, Petrov V, et al. Apolipoprotein-mediated transport of nanoparticle-bound drugs across the blood-brain barrier. J Drug Target. 2002;10(4):317-325.

62. Schäffler M, Semmler-Behnke M, Sarioglu H, et al. Serum protein identification and quantification of the corona of 5, 15 and $80 \mathrm{~nm}$ gold nanoparticles. Nanotechnology. 2013;24(26):265103. 


\section{Supplementary materials}
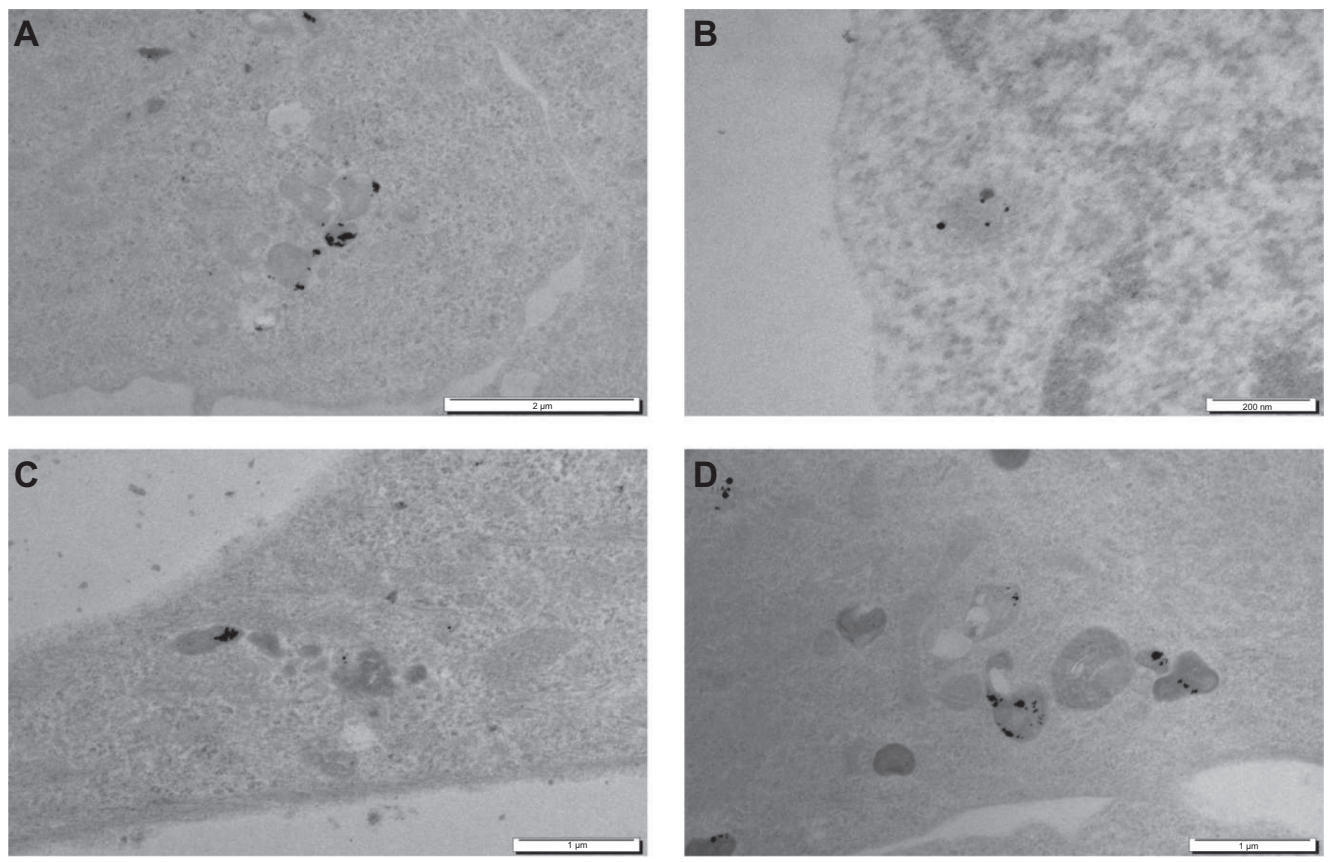

Figure SI Cellular uptake of gold nanoparticles of different sizes in pure deionized water. Transmission electron microscopy images of neuroblastoma cells incubated with $1 \mathrm{mg} / \mathrm{L}$ gold nanoparticles in pure deionized water of $6 \mathrm{~nm}(\mathbf{A}), 12 \mathrm{~nm}(\mathbf{B})$, or $19 \mathrm{~nm}$ (C) or polydispersed (D) for 24 hours.

Table SI List of the most abundant proteins identified on Au-NPw, Au-NPp, and Au-NPd by mass spectroscopy

\begin{tabular}{|c|c|c|c|c|c|}
\hline \multirow[t]{2}{*}{ Accession } & \multirow[t]{2}{*}{ Mass (kDa) } & \multirow[t]{2}{*}{ Name } & \multicolumn{3}{|l|}{ emPAI } \\
\hline & & & Au-NPw & Au-NPp & Au-NPd \\
\hline ALBU_BOVIN & 71 & Serum albumin & 7.69 & 8.09 & 25.79 \\
\hline ANT3_BOVIN & 53 & Antithrombin-III & 6.82 & 4.78 & 4.12 \\
\hline HBBF_BOVIN & 16 & Hemoglobin fetal subunit beta & 5.85 & 7.3 & 16.92 \\
\hline HBA_BOVIN & 15 & Hemoglobin subunit alpha & 4.02 & 3.1 & 2.35 \\
\hline APOE_BOVIN & 36 & Apolipoprotein E & 3.89 & 2.44 & 1.88 \\
\hline TRFE_BOVIN & 80 & Serotransferrin & 2.77 & 1.73 & 3.25 \\
\hline ACTB_BOVIN & 42 & Actin cytoplasmic I & 2.62 & 1.88 & 1.13 \\
\hline IBP2_BOVIN & 35 & Insulin-like growth factor-binding protein & 2.24 & 2.24 & 2.88 \\
\hline THRB_BOVIN & 72 & Prothrombin & 2.05 & 1.79 & 2.05 \\
\hline CO3_BOVIN & 189 & Complement $\mathrm{C} 3$ & 1.94 & 1.66 & 0.95 \\
\hline IPSP_BOVIN & 45 & Plasma serine protease inhibitor & 1.67 & 2.79 & 3.37 \\
\hline GELS_BOVIN & 81 & Gelsolin & 1.59 & 2.29 & 1.59 \\
\hline AIAT_BOVIN & 46 & Alpha-I-antiproteinase & $\mathrm{I} .44$ & 0.99 & 1.28 \\
\hline FETUA_BOVIN & 39 & Alpha-2-HS-glycoprotein & 1.44 & 1.44 & 2.37 \\
\hline RAPIB_BOVIN & 21 & Ras-related protein Rap-Ib & 1.43 & 1.43 & 0.81 \\
\hline APOAI_BOVIN & 30 & Apolipoprotein A-I & 1.3 & 2.49 & 4.29 \\
\hline FIBB_BOVIN & 54 & Fibrinogen beta chain & 1.29 & 1.04 & 1.43 \\
\hline CAPI_BOVIN & 52 & Adenylyl cyclase-associated protein I & I.I & 0.64 & 0.06 \\
\hline EFIAI_BOVIN & 50 & Elongation factor I-alpha I & 0.77 & 0.88 & 1.14 \\
\hline FI3A_BOVIN & 23 & Coagulation factor XIII A & 0.51 & 0.51 & 0.73 \\
\hline TETN_BOVIN & 23 & Tetranectin & 0.15 & 2.03 & 1.64 \\
\hline CFAH_BOVIN & 145 & Complement factor $\mathrm{H}$ & & 1.55 & 0.83 \\
\hline TSPI_BOVIN & 133 & Thrombospondin-I & & 0.66 & 1.02 \\
\hline KNGI_BOVIN & 70 & Kininogen-I & & 1.18 & 1.08 \\
\hline CIQB_BOVIN & 27 & Complement $\mathrm{Clq}$ subcomponent subunit $\mathrm{B}$ & & 1.28 & 2.66 \\
\hline
\end{tabular}

Abbreviations: Au-NPs, gold nanoparticles; Au-NPd, Au-NPs prepared in dextran; Au-NPp, Au-NPs prepared in polyethylene glycol; Au-NPw, Au-NPs in pure deionized water; emPAl, Exponentially Modified Protein Abundance Index. 


\section{Publish your work in this journal}

The International Journal of Nanomedicine is an international, peerreviewed journal focusing on the application of nanotechnology in diagnostics, therapeutics, and drug delivery systems throughout the biomedical field. This journal is indexed on PubMed Central, MedLine, CAS, SciSearch $\AA$, Current Contents $\AA /$ Clinical Medicine,

Journal Citation Reports/Science Edition, EMBase, Scopus and the Elsevier Bibliographic databases. The manuscript management system is completely online and includes a very quick and fair peer-review system, which is all easy to use. Visit http://www.dovepress.com/ testimonials.php to read real quotes from published authors.

Submit your manuscript here: http://www.dovepress.com/international-journal-of-nanomedicine-journal 